\title{
Idiosyncratic Sectoral Growth, Balanced Growth, and Sectoral Linkages
}

Andrew Foerster, Eric LaRose, and Pierre-Daniel Sarte

I

n general, there is substantial heterogeneity in value added, gross output, and production patterns across sectors within the US economy. There is also considerable asymmetry in intermediate goods linkages; that is, some sectors are much larger suppliers of intermediate goods to different sectors, on average, than others. Such heterogeneity suggests that there may be significant differences in the extent to which shocks to individual sectors not only affect aggregate output, but also transmit to other sectors. ${ }^{1}$

In this paper, in contrast to previous literature focusing on shorterrun variations in economic activity, we explore how longer-run growth in different sectors affects other sectors and overall aggregate growth. We consider a neoclassical multisector growth model with sector-specific capital and linkages between sectors in intermediate goods. In particular, we investigate the properties of a balanced growth path where total factor productivity (TFP) growth is sector-specific. We derive a relatively simple formula that simultaneously captures all relationships between value-added growth and TFP growth across sectors. We then study the effect of changes in TFP growth in one sector on value-added growth in every other sector. In addition, we can use the Divisia index for aggregate value-added growth to calculate the effect of a change in TFP growth in a given sector on aggregate GDP growth. Finally, using

- The views expressed herein are those of the authors and do not necessarily reflect those of the Federal Reserve Bank of Richmond, the Federal Reserve Bank of San Francisco, or the Federal Reserve System. We thank Caroline Davis, Toan Phan, Santiago Pinto, and John Weinberg for helpful comments.

${ }^{1}$ See, for instance, Acemoglu, Carvalho, Ozdaglar, and Tahbaz-Salehi (2012); Foerster, Sarte, and Watson (2011); Atalay (2017); and Miranda-Pinto (2018).

DOI: https://doi.org/10.21144/eq1040202 
data on value-added growth for each sector over the period 1948-2014, we recover each sector's model-implied mean TFP growth over this period and examine how sectoral changes in TFP growth in practice carry over to other sectors.

In all three of the above exercises, we also consider a special case of our model without capital. This case collapses to the model considered by Hulten (1978), or Acemoglu et al. (2012). In that model, absent capital, the impact of a level change in sectoral TFP on GDP is entirely captured by that sector's share in GDP. ${ }^{2}$ We show that a version of this result also holds in growth rates along the balanced growth path. In that special case, other microeconomic details of the environment become irrelevant as long as we can observe the distribution of valueadded shares across sectors.

More generally, in the benchmark model, value-added growth and the effects of changes in TFP growth in a given sector on GDP growth depend on that sector's capital intensity, its share of value added in gross output, and the degree to which its goods are used as intermediates by other sectors. In this regard, in a multisector model with capital, it becomes important to have information pertaining to the underlying microeconomic structure of the economy beyond what is captured in shares. Fortunately, the model delivers a simple expression of relevant parameters that can easily be constructed from sectoral-level data provided by government agencies.

Using such data, we can quantify the effects of changes in sectoral TFP growth and compare these results to the special case of our model where a version of Hulten (1978) holds in growth rates. In the seven sectors we consider in this paper, sectors vary widely in their shares of capital in value added and value added in total output, and some sectors are considerably more important suppliers of intermediate goods than others. Overall, we find that adding capital to the model creates substantial spillovers across sectors resulting from TFP growth changes that, for every sector, substantially increase the responsiveness of GDP growth to such changes. These spillover effects are larger for sectors more integral to sectoral linkages in intermediates, a finding consistent with the literature we discuss below.

\footnotetext{
${ }^{2}$ Pasten, Schoenle, and Weber (2018) and Baqaee and Farhi (2018) show that, even in a model without capital, this result may not hold due to factors such as heterogeneous price rigidity and nonlinearities in production.
} 


\section{RELATED LITERATURE}

The modern literature on multisector growth models started with the real business cycle model presented in Long and Plosser (1983). In their model, a representative agent chooses labor inputs and commodity inputs to $n$ sectors, with linkages between sectors in inputs and uncorrelated exogenous shocks to each sector. Taking the model to the data with six sectors, they found substantial comovement in output across sectors; furthermore, shocks to individual sectors generally led to large aggregate fluctuations, particularly for sectors that heavily served as inputs in production.

For many years, there existed a sense that at more disaggregated levels than that of Long and Plosser (1983), idiosyncratic sectoral shocks should fail to affect aggregate volatility. Lucas (1981), in particular, argued that in an economy with disaggregated sectors, many sector-specific shocks would occur within a given period and roughly cancel each other out in a way consistent with the Law of Large Numbers. Dupor (1999) helped formalize the conditions under which the intuition in Lucas (1981) would apply. He considered an $n$-sector economy with linkages between firms in intermediates as well as full depreciation of capital. Assuming all sectors sold nonzero amounts to all other sectors, and that every row total in the matrix of linkages was the same (i.e., every sector is equally important as an input supplier to all other sectors), Dupor found that aggregate volatility converged toward zero at a rate of $\sqrt{n}$; the underlying structure of the input-output matrix was irrelevant as long as it satisfied those conditions.

Horvath (1998) countered that Dupor's irrelevance theorem failed to hold because, in practice, sectors are not uniformly important as input suppliers to other sectors. He observed that at high levels of disaggregation in US data, the matrix of input-output linkages became quite sparse, with only a few sectors selling widely to others; consequently, sectoral shocks could explain a significant share of aggregate volatility, which would decline at a rate much slower than $\sqrt{n}$. (Horvath [2000] showed that his earlier result still held in more general models including, among other things, linkages between sectors in investments.) Acemoglu et al. (2012) expand on Horvath's idea by analyzing the network structure of linkages and conclude that it is the asymmetry, rather than the sparseness, of input-output linkages that determines the decay rate of aggregate volatility. In a multisector model with linkages between sectors in investment as well as intermediates, Foerster, Sarte, and Watson (2011) find evidence of a high level of asymmetry in the data, consistent with Acemoglu et al. (2012). They also show that, starting with the Great Moderation around 1983, roughly half the variation in aggregate output stems from sectoral shocks. 
As an additional perspective on the failure of sectoral shocks to average out, Gabaix (2011) also points out that the "averaging out" argument will not hold when the distribution of firms (or sectors) is fat-tailed, meaning a few large firms (or sectors) dominate the economy. In such a case, aggregate volatility decays at rate $\frac{1}{\ln n}$, and idiosyncratic movements can cause large variations in output growth.

While it should be clear from this section that the literature on multisector growth models has mostly focused on the relationship between aggregate and sectoral volatility, this paper focuses instead on the relationship between aggregate and sectoral growth. The arguments of Horvath (1998), Acemoglu et al. (2012), and others regarding the nature of input-output linkages still hold relevance for sectoral growth. In that vein, the analysis herein builds more directly on the work of Ngai and Pissarides (2007). In that paper, the authors focus on the effects of different TFP growth rates across sectors on sectoral employment shares. The model we present extends their work by explicitly capturing all pairwise linkages in intermediate goods in the economy while additionally allowing every sector to produce capital.

\section{ECONOMIC ENVIRONMENT}

We consider an economy with $n$ sectors. For simplicity, we assume that utility is linear in the final consumption good. Preferences are given by

$$
\begin{gathered}
\mathbf{E}_{0} \sum_{t=0}^{\infty} \beta^{t} C_{t} \\
C_{t}=\prod_{j=1}^{n}\left(\frac{c_{j, t}}{\theta_{j}}\right)^{\theta_{j}}, \sum_{j=1}^{n} \theta_{j}=1,
\end{gathered}
$$

where $C_{t}$ represents an aggregate consumption bundle taken to be the numeraire good.

Gross output in a sector $j$ results from combining value added and materials output according to

$$
y_{j, t}=\left(\frac{v_{j, t}}{\gamma_{j}}\right)^{\gamma_{j}}\left(\frac{m_{j, t}}{1-\gamma_{j}}\right)^{1-\gamma_{j}},
$$

where $y_{j, t}, v_{j, t}$, and $m_{j, t}$ denote gross output, value added, and materials output, respectively, used by sector $j$ at time $t$. Materials output in a given sector $j$ results from combining different intermediate materials 
from all other sectors, as described by the production function,

$$
m_{j, t}=\prod_{i=1}^{n}\left(\frac{m_{i j, t}}{\phi_{i j}}\right)^{\phi_{i j}}, \sum_{i=1}^{n} \phi_{i j}=1,
$$

where $m_{i j, t}$ denotes the use of materials produced in sector $i$ by sector $j$ at time $t$.

Value added in sector $j$ is produced using capital and labor,

$$
v_{j, t}=z_{j, t}\left(\frac{k_{j, t}}{\alpha_{j}}\right)^{\alpha_{j}}\left(\frac{\ell_{j, t}}{1-\alpha_{j}}\right)^{1-\alpha_{j}}
$$

where $z_{j, t}$ denotes a technical shift parameter that scales production of value added, which we refer to as value-added TFP.

Capital is sector-specific, so that output from only sector $j$ can be used to produce capital for sector $j$, and it accumulates according to the law of motion,

$$
k_{j, t+1}=x_{j, t}+(1-\delta) k_{j, t},
$$

where $x_{j, t}$ represents investment in sector $j$ at time $t$ and $\delta$ denotes the depreciation rate of capital.

Goods market clearing requires that

$$
c_{j, t}+\sum_{i=1}^{n} m_{j i, t}+x_{j, t}=y_{j, t},
$$

while labor market clearing requires that

$$
\sum_{j=1}^{n} \ell_{j, t}=1
$$

Here, we assume that aggregate labor supply is inelastic and set to one. We also assume that labor can move freely across sectors so that workers earn the same wage, $w_{t}$, in all sectors.

Finally, we assume that TFP growth in sector $j, \Delta \ln z_{j, t}$, follows an $\operatorname{AR}(1)$ process,

$$
\Delta \ln z_{j, t}=(1-\rho) g_{j}+\rho \Delta \ln z_{j, t-1}+\eta_{j, t},
$$

where $\rho<1$ and $\eta_{j, t} \sim \mathcal{D}$ with mean zero for each $j$.

\section{PLANNER'S PROBLEM}

The economy we have just described presents no frictions, so that decentralized allocations in the competitive equilibrium are optimal. Thus, we derive these allocations by solving the following planner's 
problem:

$$
\max \mathcal{L}=\sum_{t=0}^{\infty} \beta^{t} \prod_{j=1}^{n}\left(\frac{c_{j, t}}{\theta_{j}}\right)^{\theta_{j}}
$$

such that $\forall j$ and $t$,

$$
\begin{gathered}
c_{j, t}+\sum_{i=1}^{n} m_{j i, t}+x_{j, t}=\left(\frac{v_{j, t}}{\gamma_{j}}\right)^{\gamma_{j}}\left(\frac{m_{j, t}}{1-\gamma_{j}}\right)^{1-\gamma_{j}}, \\
m_{j, t}=\prod_{i=1}^{n}\left(\frac{m_{i j, t}}{\phi_{i j}}\right)^{\phi_{i j}}, \\
v_{j, t}=z_{j, t}\left(\frac{k_{j, t}}{\alpha_{j}}\right)^{\alpha_{j}}\left(\frac{\ell_{j, t}}{1-\alpha_{j}}\right)^{1-\alpha_{j}}, \\
k_{j, t+1}=x_{j, t}+(1-\delta) k_{j, t}
\end{gathered}
$$

and $\forall t$,

$$
\sum_{j=1}^{n} \ell_{j, t}=1
$$

Let $p_{j, t}^{y}, p_{j, t}^{v}, p_{j, t}^{m}$, and $p_{j, t}^{x}$ denote the Lagrange multipliers associated with, respectively, the resource constraint (2), the production of value added (4), the production of materials (3), and the capital accumulation equation (5) in sector $j$ at date $t$.

The first-order conditions for optimality yield

$$
\frac{\theta_{j} C_{t}}{c_{j, t}}=p_{j, t}^{y} .
$$

This expression also defines an ideal price index,

$$
1=\prod_{j=1}^{n}\left(p_{j, t}^{y}\right)^{\theta_{j}}
$$

We additionally have that

$$
p_{j, t}^{v} v_{j, t}=\gamma_{j} p_{j, t}^{y} y_{j, t}
$$

Likewise,

$$
p_{j, t}^{m} m_{j, t}=\left(1-\gamma_{j}\right) p_{j, t}^{y} y_{j, t} .
$$

The above two expressions define a price index for gross output,

$$
p_{j, t}^{y}=\left(p_{j, t}^{v}\right)^{\gamma_{j}}\left(p_{j, t}^{m}\right)^{1-\gamma_{j}} .
$$


In addition, we have that

$$
p_{i, t}^{y} m_{i j, t}=\phi_{i j} p_{j, t}^{m} m_{j, t},
$$

which gives material prices in terms of gross output prices,

$$
p_{j, t}^{m}=\prod_{i=1}^{n}\left(p_{i, t}^{y}\right)^{\phi_{i j}},
$$

and

$$
w_{t} \ell_{j, t}=\left(1-\alpha_{j}\right) p_{j, t}^{v} v_{j, t},
$$

where $w_{t}$ is the Lagrange multiplier associated with the labor market clearing condition (6).

From the law of motion for capital accumulation, we have that

$$
p_{j, t}^{x}=p_{j, t}^{y} .
$$

Finally, the Euler equation associated with optimal investment dictates

$$
p_{j, t}^{x}=\beta \mathbf{E}_{t}\left[\alpha_{j} \frac{p_{j, t+1}^{v} v_{j, t+1}}{k_{j, t+1}}+p_{j, t+1}^{x}(1-\delta)\right] .
$$

The first-order conditions give rise to natural expressions of the model parameters as shares that are readily available in the data. In particular, $\theta_{j}$ represents the share of sector $j$ in nominal consumption, and $\gamma_{j}$ represents the share of value added in total output in sector $j$, while $\phi_{i j}$ represents materials purchased from sector $i$ by sector $j$ as a share of total materials purchased in sector $j$. Furthermore, $1-\alpha_{j}$ equals the share of total wages in nominal value added in sector $j$, and consequently, $\alpha_{j}$ represents capital's share in nominal value added. Nominal value added in sector $j$ in this economy is then given by $p_{j, t}^{v} v_{j, t}=\gamma_{i} p_{j, t}^{y} y_{j, t}$, and it follows that $G D P_{t}=\sum_{j} p_{j, t}^{v} v_{j, t}$.

In the remainder of this paper, we adopt the following notation: $\Gamma_{d}=\operatorname{diag}\left\{\gamma_{j}\right\}, \alpha_{d}=\operatorname{diag}\left\{\alpha_{j}\right\}, \Theta=\left(\theta_{1}, \ldots, \theta_{n}\right)$, and $\Phi=\left\{\phi_{i j}\right\}$.

\section{Some Benchmark Results in Levels}

A special case of the economic environment presented above is one where $\alpha_{j}=0 \forall j$, which, absent any growth in sectoral TFP or shocks, reduces to the static economies of Hulten (1978) or Acemoglu et al. (2012). In this case, aggregate value added, or GDP, is given by the consumption bundle $C_{t}$ and

$$
\frac{\partial \ln G D P_{t}}{\partial \ln z_{j, t}}=s_{j}^{v} \forall t
$$

where $s_{j}^{v}$ is sector $j$ 's value-added share in GDP, and we summarize these shares in a vector, $\mathbf{s}^{v}=\left(s_{1}^{v}, \ldots, s_{n}^{v}\right)$, given by

$$
\mathbf{s}^{v}=\Theta\left(I-\left(I-\Gamma_{d}\right) \Phi^{\prime}\right)^{-1} \Gamma_{d} .
$$


As shown in Hulten (1978), in this special case, a sector's value-added share entirely captures the effect of a level change in TFP on GDP. Accordingly, Acemoglu et al. (2012) refer to the object $\Theta(I-(I-$ $\left.\left.\Gamma_{d}\right) \Phi^{\prime}\right)^{-1} \Gamma_{d}$ as the influence vector.

A model with capital is dynamic but, in the long run, converges to a steady state in levels absent any sectoral TFP growth. With a discount factor $\beta$ close to 1 , the effect of a level change in sectoral log TFP on log GDP continues to be given primarily by sectoral shares, as in equation (8). In other words, Hulten's (1978) result continues to hold in an economy with capital in that the variation in the effects of sectoral TFP changes on GDP is determined by the variation in sectoral shares. In this case, however, sectoral shares need to be adjusted by a factor that is constant across sectors and approximately equal to the inverse of the mean employment share.

With exogenous sectoral TFP growth, the economy no longer achieves a steady state in levels. Instead, with constant sectoral TFP growth, the steady state of the economy may be defined in terms of sectoral growth rates along a balanced growth path. Along this path, the effects of TFP growth changes on GDP growth involve additional considerations. In particular, sectoral linkages in intermediates mean that changes in sectoral TFP growth in one sector potentially affect valueadded growth rates in every other sector and, therefore, can impact overall GDP growth beyond changes in shares. These sectoral linkages consequently create a multiplier effect that, as we show below, can lead to a total impact of a TFP growth change in a given sector that is several times larger than that sector's share in GDP.

\section{SOLVING FOR BALANCED GROWTH}

We now allow for each sector to grow at a different rate along a balanced growth path. In particular, we derive and explore the relationships that link different sectoral growth rates to each other and study how TFP growth rates in one sector affect all other sectors and the aggregate balanced growth path.

Consider the case where $z_{j, t}$ is growing at a constant rate along a nonstochastic steady-state path, that is $\eta_{j, t}=0$ and $\Delta \ln z_{j, t}=g_{j} \forall j$, $t$. Moreover, the resource constraint (2) in each sector requires that all variables in that equation grow at the same constant rate along a balanced growth path. Therefore, we normalize the model's variables in each sector by a sector-specific factor $\mu_{j, t}$. In particular, we define $\tilde{y}_{j, t}=y_{j, t} / \mu_{j, t}, \tilde{c}_{j, t}=c_{j, t} / \mu_{j, t}, \tilde{m}_{j i, t}=m_{j i, t} / \mu_{j, t}$, and $\tilde{x}_{j, t}=x_{j, t} / \mu_{j, t}$. We show that detrending the economy yields a system of equations that is stationary in the normalized variables along the balanced growth path 
and where the vector $\mu_{t}=\left(\mu_{1, t}, \ldots, \mu_{n, t}\right)^{\prime}$ can be expressed as a function of the underlying parameters of the model only.

\section{Detrending the Economy}

The capital accumulation equation in sector $j$ can be written under this normalization as

$$
k_{j, t+1}=\tilde{x}_{j, t} \mu_{j, t}+(1-\delta) k_{j, t},
$$

so that

$$
\tilde{k}_{j, t+1}=\tilde{x}_{j, t}+(1-\delta) \tilde{k}_{j, t}\left(\frac{\mu_{j, t-1}}{\mu_{j, t}}\right),
$$

where $\tilde{k}_{j, t}=k_{j, t} / \mu_{j, t-1}$.

Using this last equation, we can write value added in sector $j$ as

$$
v_{j, t}=z_{j, t}\left(\frac{\tilde{k}_{j, t} \mu_{j, t-1}}{\alpha_{j}}\right)^{\alpha_{j}}\left(\frac{\ell_{j, t}}{1-\alpha_{j}}\right)^{1-\alpha_{j}} .
$$

The aggregate labor constraint in each period, $\sum_{j} \ell_{j, t}=1$, implies that the labor shares, $\ell_{j, t}$, are already normalized: $\tilde{\ell}_{j, t}=\ell_{j, t}$. Then defining $\tilde{v}_{j, t}=v_{j, t} /\left(z_{j, t}\left(\mu_{j, t-1}\right)^{\alpha_{j}}\right)$, the expression for value added becomes

$$
\tilde{v}_{j, t}=\left(\frac{\tilde{k}_{j, t}}{\alpha_{j}}\right)^{\alpha_{j}}\left(\frac{\ell_{j, t}}{1-\alpha_{j}}\right)^{1-\alpha_{j}} .
$$

The equation for materials used in sector $j$ can be written in normalized terms as

$$
\tilde{m}_{j, t}=\prod_{i=1}^{n}\left(\frac{\tilde{m}_{i j, t}}{\phi_{i j}}\right)^{\phi_{i j}}
$$

where $\tilde{m}_{j, t}=m_{j, t} / \prod_{i=1}^{n} \mu_{i, t}^{\phi_{i j}}$. It follows that gross output in sector $j$ becomes, in normalized terms,

$$
\tilde{y}_{j, t} \mu_{j, t}=\left(\frac{\tilde{v}_{j, t} z_{j, t} \mu_{j, t}^{\alpha_{j}}}{\gamma_{j}}\right)^{\gamma_{j}}\left(\frac{\tilde{m}_{j, t} \prod_{i=1}^{n} \mu_{i, t}^{\phi_{i j}}}{1-\gamma_{j}}\right)^{1-\gamma_{j}},
$$

which may be rewritten as

$$
\tilde{y}_{j, t}=\left(\frac{\tilde{v}_{j, t}}{\gamma_{j}}\right)^{\gamma_{j}}\left(\frac{\tilde{m}_{j, t}}{1-\gamma_{j}}\right)^{1-\gamma_{j}}\left[\frac{z_{j, t}^{\gamma_{j}} \mu_{j, t-1}^{\gamma_{j} \alpha_{j}}}{\mu_{j, t}} \prod_{i=1}^{n} \mu_{i, t}^{\left(1-\gamma_{j}\right) \phi_{i j}}\right] .
$$

Observe that for the detrended variables to be constant along a balanced growth path, it must be the case that the expression in square 
brackets is also constant along that path. Thus, we can use equation (9) to solve for $\mu_{j, t}$ as a function of the model parameters. In particular, we can rewrite the term in square brackets as

$$
\frac{z_{j, t}^{\gamma_{j}} \mu_{j, t-1}^{\gamma_{j} \alpha_{j}} \mu_{j, t}^{\gamma_{j} \alpha_{j}-1}}{\mu_{j, t}^{\gamma_{j} \alpha_{j}}} \prod_{i=1}^{n} \mu_{i, t}^{\left(1-\gamma_{j}\right) \phi_{i j}}
$$

where we aim for the growth rate of $\mu_{j, t}$ to be constant. Thus, without loss of generality, we choose $\mu_{j, t}$ such that

$$
z_{j, t}^{\gamma_{j}} \mu_{j, t}^{\gamma_{j} \alpha_{j}-1} \prod_{i=1}^{n} \mu_{i, t}^{\left(1-\gamma_{j}\right) \phi_{i j}}=1,
$$

which in logs gives

$$
\gamma_{j} \ln z_{j, t}+\left(\gamma_{j} \alpha_{j}-1\right) \ln u_{j, t}+\sum_{i=1}^{n}\left(1-\gamma_{j}\right) \phi_{i j} \ln \mu_{i, t}=0 .
$$

In matrix form, with $z_{t}=\left(z_{1, t}, \ldots, z_{n, t}\right)^{\prime}$, equation (10) becomes

$$
\Gamma_{d} \ln z_{t}+\left(\Gamma_{d} \alpha_{d}-I\right) \ln \mu_{t}+\left(I-\Gamma_{d}\right) \Phi^{\prime} \ln \mu_{t}=0 .
$$

It follows that along a balanced growth path,

$$
\Delta \ln \mu_{t}=\left(I-\Gamma_{d} \alpha_{d}-\left(I-\Gamma_{d}\right) \Phi^{\prime}\right)^{-1} \Gamma_{d} g_{z},
$$

where $g_{z}=\left(g_{1}, \ldots, g_{n}\right)^{\prime}$.

\section{Sectoral Value Added and GDP along a Balanced Growth Path}

Having derived expressions in terms of the normalizing factors for $\mu_{j, t}$, we now derive the normalizing factors for value added in each sector. By construction, these factors in turn will grow at the same rate as value added in each sector. As given above, the normalizing factor for value added in sector $j$, denoted as $\mu_{j, t}^{v}$, is $z_{j, t} \mu_{j, t-1}^{\alpha_{j}}$. In vector form, this becomes

$$
\Delta \ln \mu_{t}^{v}=\Delta \ln z_{t}+\alpha_{d}\left(I-\Gamma_{d} \alpha_{d}-\left(I-\Gamma_{d}\right) \Phi^{\prime}\right)^{-1} \Gamma_{d} \Delta \ln z_{t-1},
$$

so that along a balanced growth path,

$$
\Delta \ln \mu_{t}^{v}=\left[I+\alpha_{d}\left(I-\Gamma_{d} \alpha_{d}-\left(I-\Gamma_{d}\right) \Phi^{\prime}\right)^{-1} \Gamma_{d}\right] g_{z}
$$

In other words, in this economy, TFP growth in each sector potentially affects value-added growth in every other sector through a matrix that summarizes all linkages in the economy, $\left[I+\alpha_{d}\left(I-\Gamma_{d} \alpha_{d}-\left(I-\Gamma_{d}\right) \Phi^{\prime}\right)^{-1} \Gamma_{d}\right]$. Moreover, these effects may be 
summarized analytically by

$$
\frac{\partial \Delta \ln \mu_{t}^{v}}{\partial g_{z}}=\left[I+\alpha_{d}\left(I-\Gamma_{d} \alpha_{d}-\left(I-\Gamma_{d}\right) \Phi^{\prime}\right)^{-1} \Gamma_{d}\right],
$$

where the element in row $i$ and column $j$ of this matrix represents the effect of an increase in TFP growth in sector $j$ on value-added growth rates in sector $i$ :

$$
\frac{\partial \Delta \ln \mu_{i, t}^{v}}{\partial g_{j}}=1+\alpha_{i} \gamma_{j} \xi_{i j} \text { if } i=j,
$$

where $\left(I-\Gamma_{d} \alpha_{d}-\left(I-\Gamma_{d}\right) \Phi^{\prime}\right)^{-1}=\left\{\xi_{i j}\right\}$, or

$$
\frac{\partial \Delta \ln \mu_{i, t}^{v}}{\partial g_{j}}=\alpha_{i} \gamma_{j} \xi_{i j} \text { if } i \neq j \text {. }
$$

As mentioned above, growth rates in every sector depend on TFP growth rates in every sector because of the linkages between sectors in intermediate goods. The matrix $\left(I-\Gamma_{d} \alpha_{d}-\left(I-\Gamma_{d}\right) \Phi^{\prime}\right)^{-1} \Gamma_{d}$ suggests that, all else equal, TFP growth changes in sectors that are more capital intensive (i.e., where $\alpha_{j}$ is higher) and have higher shares of value added in gross output (i.e., where $\gamma_{j}$ is higher) will tend to have larger effects on other sectors. Additionally, more capital-intensive sectors will tend to have larger responses to TFP growth changes in other sectors.

The expression for GDP gives us

$$
G D P_{t}=\sum_{j=1}^{n} p_{j, t}^{v} v_{j, t} .
$$

Using a standard Divisia index, we can express aggregate GDP growth as a weighted average of sectoral growth rates in real value added,

$$
\Delta \ln G D P_{t}=\sum_{j=1}^{n} s_{j, t}^{v} \Delta \ln v_{j, t},
$$

where $s_{j, t}^{v}$ is the share of sector $j$ in nominal value added, ${ }^{3}$

$$
s_{j, t}^{v}=\frac{p_{j, t}^{v} v_{j, t}}{\sum_{j=1}^{n} p_{j, t}^{v} v_{j, t}} .
$$

Define $\Delta \ln \mathbf{v}_{t}=\Delta \ln \mu_{t}^{v}$ along the balanced growth path. We may then substitute our expression for $\ln \mu_{t}^{v}$ in terms of TFP to obtain the

\footnotetext{
${ }^{3}$ These shares also hold in normalized form, so that $s_{j, t}^{v}=\frac{\tilde{p}_{j, t}^{v} \tilde{v}_{j, t}}{\sum_{j=1}^{n} \tilde{p}_{j, t}^{v} \tilde{v}_{j, t}}$, and are constant along the balanced growth path. Here we take the shares as exogenous parameters given in the data, but they can alternatively be solved as part of the steady state in normalized variables.
} 
balanced growth rate of real aggregate GDP in terms of TFP growth:

$$
\Delta \ln G D P_{t}=\mathbf{s}^{v}\left[I+\alpha_{d}\left(I-\Gamma_{d} \alpha_{d}-\left(I-\Gamma_{d}\right) \Phi^{\prime}\right)^{-1} \Gamma_{d}\right] g_{z} .
$$

This last expression implies that, with constant shares,

$$
\frac{\partial \Delta \ln G D P_{t}}{\partial g_{z}}=\mathbf{s}^{v}\left[I+\alpha_{d}\left(I-\Gamma_{d} \alpha_{d}-\left(I-\Gamma_{d}\right) \Phi^{\prime}\right)^{-1} \Gamma_{d}\right],
$$

with the effect of a change in TFP growth in sector $j$ on GDP growth then given by the $j$ th element,

$$
\frac{\partial \Delta \ln G D P_{t}}{\partial g_{j}}=\left(s_{j}^{v}+\sum_{i=1}^{n} s_{i}^{v} \alpha_{i} \gamma_{j} \xi_{i j}\right) .
$$

The above equation shows that TFP changes in sectors with higher shares of value added in gross output, and whose intermediates are more heavily used by other sectors, will have larger effects on changes in GDP growth.

\section{Balanced Growth with No Capital}

Consider the special case of our model with no capital accumulation, $\alpha_{j}=0 \forall j$. Then the formula for value added in sector $j$ becomes

$$
v_{j, t}=z_{j, t} \ell_{j, t} .
$$

Since labor supply, $\ell_{j, t}$, is already normalized as implied by the labor supply constraint, the normalizing factor for value added in sector $j$ at time $t, \mu_{j, t}^{v}$, is simply $\mu_{j, t}^{v}=z_{j, t}$, so that along a balanced growth path $\Delta \ln \mu_{t}^{v}=g_{z}$. Then we have

$$
\frac{\partial \Delta \ln \mu_{t}^{v}}{\partial g_{z}}=I
$$

so a change in TFP growth in sector $j$ changes value-added growth in sector $j$ by the same amount and has no impact on value-added growth in other sectors, even though sector $j$ is linked to other sectors through intermediate goods. From equation (16), in the model without capital, we then have along a balanced growth path

$$
\frac{\partial \Delta \ln G D P_{t}}{\partial g_{z}}=\mathbf{s}^{v}
$$

which has $j$ th element $s_{j}^{v}$. Put another way, a change in TFP growth in sector $j$ increases the growth rate of real aggregate GDP by that sector's share of value added in GDP. To a first order, the intermediate goods matrix $\Phi$ and other details are irrelevant as long as we know the value-added distribution of sectors. 
In the rest of this paper, we match this model to the data with $n=7$ sectors in order to quantify equations (13) and (15), and we also invert $\left[I+\alpha_{d}\left(I-\Gamma_{d} \alpha_{d}-\left(I-\Gamma_{d}\right) \Phi^{\prime}\right)^{-1} \Gamma_{d}\right]$ in equation (11) to obtain the implied TFP growth rates in each sector. We also use equations (16) and (17) to compare our quantitative benchmark results to those in the case without capital.

\section{DATA}

As described above, the natural expressions of several model parameters as shares make it easy to match this model to available data. All of the model parameters, consisting of the $\Phi$ matrix, the $\gamma_{j}$ 's, and the $\alpha_{j}$ 's, can be obtained through the Bureau of Economic Analysis (BEA), which provides data at various levels of industry aggregation going back to 1947.

The highest level of aggregation reported by the BEA is the fifteenindustry level. We drop one industry corresponding to Government, and then we consolidate the fourteen remaining industries into seven broader sectors: Agriculture, Forestry, Fishing, and Hunting; Mining and Utilities; Construction; Manufacturing; Wholesale and Retail Trade; Transportation and Warehousing; and Services. The sevensector level is a high enough level of aggregation to give us a broad overview of the economy, and these constructed sectors closely match the six sectors examined by Long and Plosser (1983).

To assemble the $\Phi$ matrix for our benchmark year, 2014, we rely on data from the BEA's Make-Use Tables, which at the fifteen-industry level provide a fifteen-by-fifteen matrix showing all pairwise combinations of intermediate goods purchases by one industry from another. From here, we sum intermediate goods purchases across all industries in a sector and then calculate shares of nominal intermediates from sector $i$ in sector $j$ 's total nominal intermediates accordingly (dropping intermediate purchases from the Government sector from the total). In addition to calculating the $\Phi$ matrix for 2014, we also calculate it for 1948, the earliest year for which data on value-added growth are available. Later on, we will be interested in comparing our results when using the $\Phi$ matrix for 1948 to those using the $\Phi$ matrix for 2014 to see how changes in intermediate purchases patterns across sectors have affected growth and TFP throughout the economy. The BEA provides the pairwise intermediates purchases at a higher level of disaggregation in 1948, with forty-six industries. Since every industry at the fifteenindustry level is a grouping of industries at the forty-six-industry level, we can sum intermediate goods purchases across industries in a sector as before. 
We also use the BEA's Make-Use Tables to calculate each sector's share of nominal value added in nominal gross output, $\gamma_{j}$, for 2014 by summing total value added and total gross output across industries in a sector and dividing accordingly. To calculate shares of capital in nominal value added, $\alpha_{j}$, we use the BEA's data on GDP by industry, which breaks down value added within an industry into the sum of wages paid to employees, a gross operating surplus, and taxes minus subsidies. We sum the first two components across industries in a sector, ignoring taxes and subsidies, and calculate $\alpha_{j}$ as sector $j$ 's gross operating surplus divided by the sum of its gross operating surplus and wages.

Finally, the BEA's GDP data include the total nominal value added for each industry at the fifteen-industry level for each year going back to 1947. We use the BEA's chain-type price indexes for value added in each industry to calculate these numbers in real terms, then sum across industries in a sector to obtain real value added for each sector. From here, we can easily calculate the real value-added growth rates for each sector for each year from 1948 through 2014 and take an average for each sector over this period to get mean value-added growth rates. Additionally, we can calculate a sector's share in nominal value added for each year (excluding value added from the Government sector in total value added) and average across years to obtain each sector's mean share in nominal value added.

Table 1 displays the share of nominal value added in nominal gross output, $\gamma_{j}$, and the share of capital in nominal value added, $\alpha_{j}$, for each sector. Some of these results are fairly intuitive; for instance, Construction and Wholesale and Retail Trade have the lowest (highest) shares of capital (labor) in value added, while Agriculture, Forestry, Fishing, and Hunting, and Mining and Utilities are the most capitalintensive. There is somewhat less variation in the shares of nominal value added in nominal gross output, with Manufacturing having the lowest share and Mining and Utilities having the highest.

Table 2 displays the matrix summarizing intermediate goods linkages, $\Phi$, calculated for 2014, where the element in row $i$ and column $j$ represents the percentage of all intermediate goods purchased by sector $j$ that come from sector $i$. First, it is not surprising that most sectors purchase a large share of intermediate goods from within their own sector: five of seven sectors have $\phi_{j j}$ values above 20 percent, with the Services sector purchasing over 75 percent of its intermediates from itself. It is also important to note that, in general, the $\Phi$ matrix displays substantial asymmetry. The average sector buys approximately 35 percent and 29 percent of its intermediates from Services and Manufacturing, respectively. If we exclude the diagonal entries of $\Phi$, these 
Table 1 Parameter Values for Each Sector

\begin{tabular}{llll}
\hline \hline Sector & Sector Number & $\gamma_{j}$ & $\alpha_{j}$ \\
\hline Agriculture, Forestry, Fishing, and Hunting & $(1)$ & 0.4139 & 0.7493 \\
Mining and Utilities & $(2)$ & 0.6845 & 0.7337 \\
Construction & $(3)$ & 0.5419 & 0.3659 \\
Manufacturing & $(4)$ & 0.3462 & 0.5205 \\
Wholesale and Retail Trade & $(5)$ & 0.6558 & 0.3680 \\
Transportation and Warehousing & $(6)$ & 0.4795 & 0.3865 \\
Services & $(7)$ & 0.6123 & 0.4556 \\
\hline
\end{tabular}

Table $2 \Phi$ in 2014, with All Numbers Expressed as Percentages

\begin{tabular}{llllllll}
\hline \hline Sector Number & $(1)$ & $(2)$ & $(3)$ & $(4)$ & $(5)$ & $(6)$ & $(7)$ \\
\hline$(1)$ & 39.72 & 0.04 & 0.27 & 7.20 & 0.31 & 0.02 & 0.19 \\
$(2)$ & 2.88 & 32.76 & 2.47 & 15.70 & 1.66 & 1.84 & 2.65 \\
$(3)$ & 0.96 & 3.86 & 0.03 & 0.36 & 0.41 & 1.01 & 2.64 \\
$(4)$ & 29.16 & 21.40 & 52.72 & 50.37 & 9.12 & 31.90 & 12.98 \\
$(5)$ & 10.30 & 4.10 & 24.00 & 8.03 & 7.26 & 9.23 & 3.31 \\
$(6)$ & 5.58 & 9.27 & 3.85 & 4.11 & 12.53 & 23.85 & 2.73 \\
$(7)$ & 11.39 & 28.57 & 16.65 & 14.24 & 68.70 & 32.15 & 75.51 \\
\hline
\end{tabular}

numbers are still 29 percent and 26 percent. On the other hand, Agriculture, Forestry, Fishing, and Hunting, and Construction stand out as relatively unimportant suppliers of intermediate goods to other sectors.

\section{QUANTIFYING BALANCED GROWTH RELATIONSHIPS}

As derived in equation (13), $\frac{\partial \Delta \ln \mu_{t}^{v}}{\partial g_{z}}=$ $\left[I+\alpha_{d}\left(I-\Gamma_{d} \alpha_{d}-\left(I-\Gamma_{d}\right) \Phi^{\prime}\right)^{-1} \Gamma_{d}\right]$ in the benchmark model. Table 3 shows this matrix for our seven sectors. The element in row $i$ and column $j$ shows the percentage-point increase in value-added growth in sector $i$ resulting from a 1 percentage point increase in TFP growth in sector $j$. Unsurprisingly, increases in TFP growth in sector $j$ have by far the largest impact on value-added growth rates in that same sector; all the entries on the diagonal have magnitude greater than 1, with Mining and Utilities having the largest diagonal value and Construction having the smallest. However, the off-diagonal entries still indicate substantial effects of TFP growth changes in one sector on value-added growth in another. For instance, a 1 percentage point increase in TFP 
Table 3 Effect of 1 Percentage Point Change in TFP Growth on Value-Added Growth in Percentage Points

\begin{tabular}{llllllll}
\hline Sector Number & $(1)$ & $(2)$ & $(3)$ & $(4)$ & $(5)$ & $(6)$ & $(7)$ \\
\hline$(1)$ & 1.7131 & 0.2099 & 0.0160 & 0.2751 & 0.1512 & 0.0726 & 0.4271 \\
$(2)$ & 0.0187 & 2.3645 & 0.0221 & 0.1456 & 0.0615 & 0.0572 & 0.3818 \\
$(3)$ & 0.0135 & 0.0692 & 1.2507 & 0.1032 & 0.0669 & 0.0189 & 0.1502 \\
$(4)$ & 0.0536 & 0.2371 & 0.0090 & 1.4316 & 0.0801 & 0.0405 & 0.2862 \\
$(5)$ & 0.0048 & 0.0295 & 0.0035 & 0.0332 & 1.3409 & 0.0211 & 0.2065 \\
$(6)$ & 0.0118 & 0.0653 & 0.0059 & 0.0925 & 0.0454 & 1.2808 & 0.2153 \\
$(7)$ & 0.0075 & 0.0500 & 0.0090 & 0.0538 & 0.0252 & 0.0146 & 1.7053 \\
\hline
\end{tabular}

growth in the Services sector increases value-added growth in Agriculture, Forestry, Fishing, and Hunting by about 0.43 percentage points. Overall, increases in TFP growth rates in the Services sector have particularly strong effects on value-added growth rates in other sectors, reflecting the generally high usage of intermediate goods from Services by other sectors. On the other hand, changes in TFP growth in other sectors have small effects on value-added growth in Services, in part because Services purchases a small fraction of its intermediates from other sectors. (These observations apply, to a somewhat lesser extent, to the Manufacturing sector as well.) Increases in TFP growth rates in sectors such as Construction and Agriculture, Forestry, Fishing, and Hunting, whose intermediates are not heavily used by other sectors, have tiny effects on value-added growth in other sectors. Finally, it is worth noting that Mining and Utilities and Agriculture, Forestry, Fishing, and Hunting, whose $\alpha_{j}$ values are substantially higher than those of other sectors, are, on average, the most responsive to sectoral TFP growth changes.

In the case with no capital, a TFP growth change in sector $j$ changes value-added growth in sector $j$ by the same amount and has no impact on value-added growth in other sectors. Since all the diagonal entries of the matrix $\left[I+\alpha_{d}\left(I-\Gamma_{d} \alpha_{d}-\left(I-\Gamma_{d}\right) \Phi^{\prime}\right)^{-1} \Gamma_{d}\right]$ have values above 1 , linkages increase the own-sector effect of TFP growth rate increases on value-added growth rates in every sector.

Given data on shares of each sector in nominal value added, we can then calculate the effect of changes in TFP growth in each sector on changes in aggregate GDP in the benchmark model according to equation (15). As described above, we compile data on sectoral shares in nominal value added for each year in the period 1948-2014, and then we take the mean shares in nominal value added for each sector over this period. Table 4 shows $\frac{\partial \Delta \ln G D P_{t}}{\partial g_{z}}$ calculated from these mean shares 
Table 4 Effect of 1 Percentage Point Change in TFP Growth on GDP Growth in Percentage Points

\begin{tabular}{llll}
\hline Sector & No Capital & Benchmark & Difference \\
\hline Agriculture, Forestry, Fishing, Hunting & 0.0297 & 0.0695 & 0.0398 \\
Mining and Utilities & 0.0457 & 0.2026 & 0.1569 \\
Construction & 0.0502 & 0.0712 & 0.0210 \\
Manufacturing & 0.2332 & 0.3868 & 0.1536 \\
Wholesale and Retail Trade & 0.1552 & 0.2505 & 0.0953 \\
Transportation and Warehousing & 0.0425 & 0.0794 & 0.0369 \\
Services & 0.4435 & 0.9020 & 0.4585 \\
\hline
\end{tabular}

for both cases. The first column shows the case with no capital, where each entry just equals that sector's mean share in total nominal value added. Two of the seven sectors, Services and Manufacturing, account for over two-thirds of total nominal GDP, on average. The second column shows the benchmark case, and the difference between the two cases in the third column can be interpreted as the total multiplier effect of a change in TFP growth in one sector on other sectors (including itself).

Figure 1 plots the mean value-added shares against $\frac{\partial \Delta \ln G D P_{t}}{\partial g_{z}}$ computed in the benchmark. The size of the deviation from the forty-fivedegree line indicates the size of the multiplier effects on other sectors. In absolute terms, this multiplier effect is by far the largest for the Services sector, in part reflecting the fact that the off-diagonal entries of the matrix $\left(I-\Gamma_{d} \alpha_{d}-\left(I-\Gamma_{d}\right) \Phi^{\prime}\right)^{-1} \Gamma_{d}$ are, on average, the highest for the column corresponding to Services. There are also large increases for Manufacturing, another sector important in the production of intermediate goods, and Mining and Utilities, which has a multiplier effect over three times as large as its share in GDP. This can be largely explained by the sector's high share of capital in value added and its importance as an intermediate goods supplier to itself and to the second-largest sector, Manufacturing.

To see the extent to which changes in the usage of intermediate goods across sectors, summarized in $\Phi$, have impacted the effect of TFP growth changes in a sector on changes in the growth rate of GDP, we also recompute $\frac{\partial \Delta \ln G D P_{t}}{\partial g_{z}}$ using the $\Phi$ matrix in 1948. Figure 2 plots $\frac{\partial \Delta \ln G D P_{t}}{\partial g_{z}}$ calculated in the benchmark using $\Phi$ from 2014 against the values calculated from 1948. Because we hold the other parameters constant for each sector, any changes should result from changes in the relative importance of sectors as intermediate goods suppliers to other sectors. As noted by Choi and Foerster (2017), there have been 
Figure 1 Derivative of GDP Growth with Respect to Sector TFP Growth

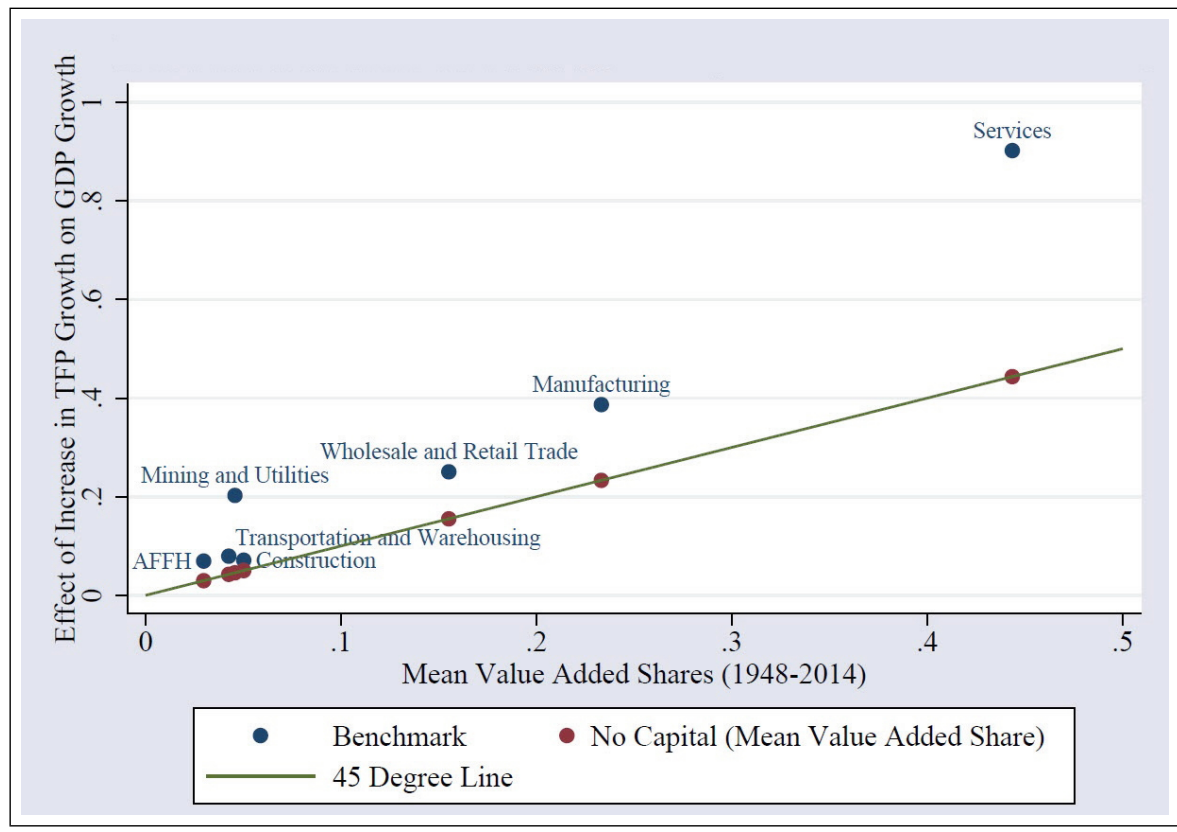

significant changes in the US economy's input-output network structure over this period. In particular, the Services sector is a markedly more important supplier of intermediate goods in 2014 than it was in 1948, driven by the increasing centrality of financial services, real estate, and other industries within this sector. On the other hand, sectors such as Manufacturing; Agriculture, Forestry, Fishing, and Hunting; and Mining and Utilities declined in importance over this period.

Consistent with these observations, Services saw the largest absolute increase in $\frac{\partial \Delta \ln G D P_{t}}{\partial g_{z}}$ over this period, while Manufacturing saw the largest absolute decrease, and Agriculture, Forestry, Fishing, and Hunting saw the largest percentage decrease. On the other hand, because $\frac{\partial \Delta \ln G D P_{t}}{\partial g_{z}}$ also depends on the shares of each sector in total nominal value added, a sector may decline in overall importance, as measured by its row total in $\Phi$, over this period while still having an increasing value of $\frac{\partial \Delta \ln G D P_{t}}{\partial g_{z}}$. For example, Mining and Utilities declines in overall importance between 1948 and 2014 but it is a much more important supplier of intermediates for the Manufacturing sector 
Figure 2 Effect of TFP Growth on GDP Growth, $1948 \Phi$ vs. $2014 \Phi$

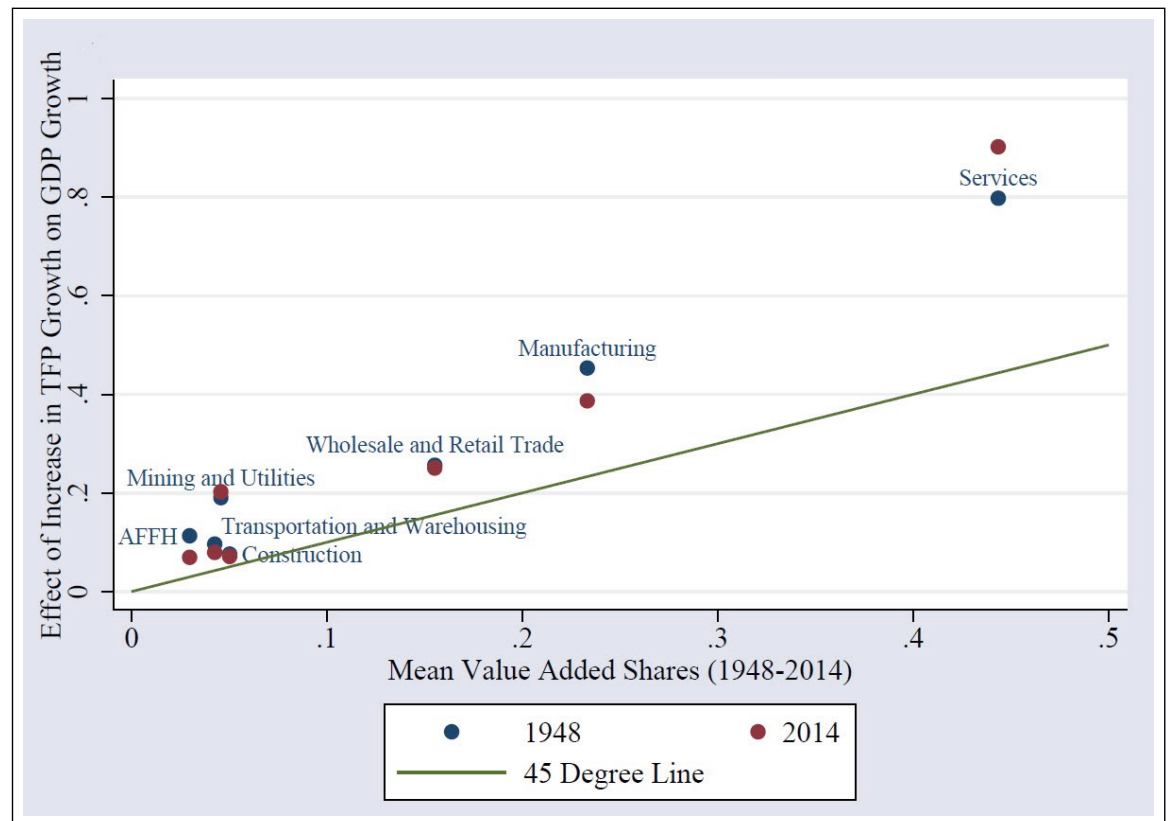

in 2014 than in 1948, largely explaining why Mining and Utilities sees a slight overall increase in $\frac{\partial \Delta \ln G D P_{t}}{\partial g_{z}}$.

As a final exercise, given data on value-added growth, we can invert the matrix $I+\alpha_{d}\left(I-\Gamma_{d} \alpha_{d}-\left(I-\Gamma_{d}\right) \Phi^{\prime}\right)^{-1} \Gamma_{d}$ to obtain the implied TFP growth rates in the benchmark:

$$
g_{z}=\left[I+\alpha_{d}\left(I-\Gamma_{d} \alpha_{d}-\left(I-\Gamma_{d}\right) \Phi^{\prime}\right)^{-1} \Gamma_{d}\right]^{-1} \Delta \ln \mu_{t}^{v}
$$

With no capital, this expression simply becomes

$$
g_{z}=\Delta \ln \mu_{t}^{v} .
$$

For each of our seven sectors, we take an average of their real valueadded growth rates over the period 1948-2014 and then calculate the implied mean TFP growth rates over this period. Figure 3 plots observed mean value-added growth against the model-implied mean TFP growth in the benchmark case and the case with no capital, where in the latter case all points lie on the forty-five-degree line. In the benchmark, all points lie well to the left this line. The decrease is largest in absolute terms for Agriculture, Forestry, Fishing, and Hunting and, consistent with intuition, is generally larger for sectors with larger val- 
Figure 3 Implied Mean TFP Growth, 1948-2014

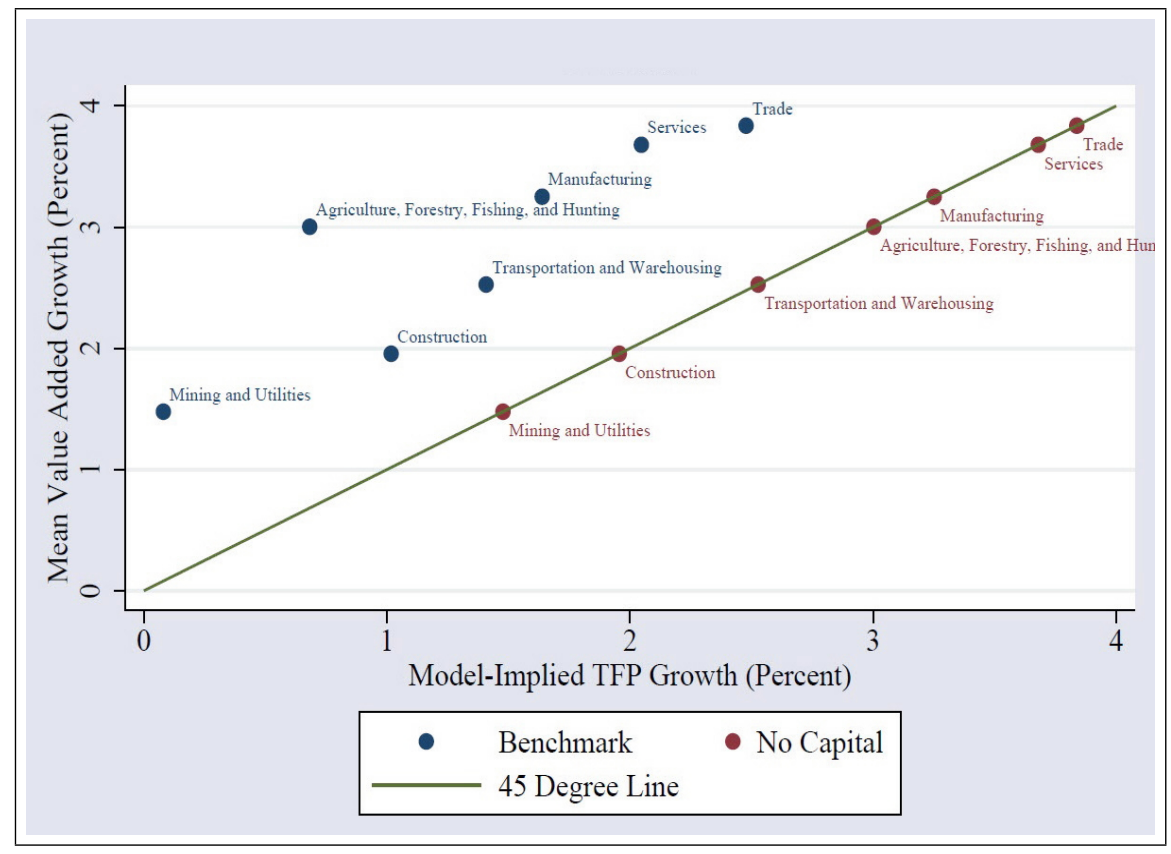

ues of $\alpha_{j}$. The implied mean TFP growth for Mining and Utilities is just 0.08 percent.

Additionally, for the benchmark case, we calculate implied mean TFP growth rates using the $\Phi$ matrix for 1948 and compare the results to those using the $\Phi$ matrix for 2014. As shown in Figure 4, changes in patterns of intermediate goods usage between 1948 and 2014 have very little impact on implied mean TFP growth rates.

\section{CONCLUSION}

Our analysis suggests that linkages between sectors in intermediate goods, and capital intensities of different sectors, lead to substantial effects of sector-specific TFP growth changes on value-added growth. TFP growth changes in sectors such as Manufacturing and Services, which account for a large share of the intermediate goods shares of other sectors, have especially large impacts on value-added growth in other sectors. On the other hand, changes in the input-output structure of the US economy from 1948 to 2014 have had a modest impact on 
Figure 4 Implied Mean TFP Growth, $1948 \Phi$ vs. $2014 \Phi$

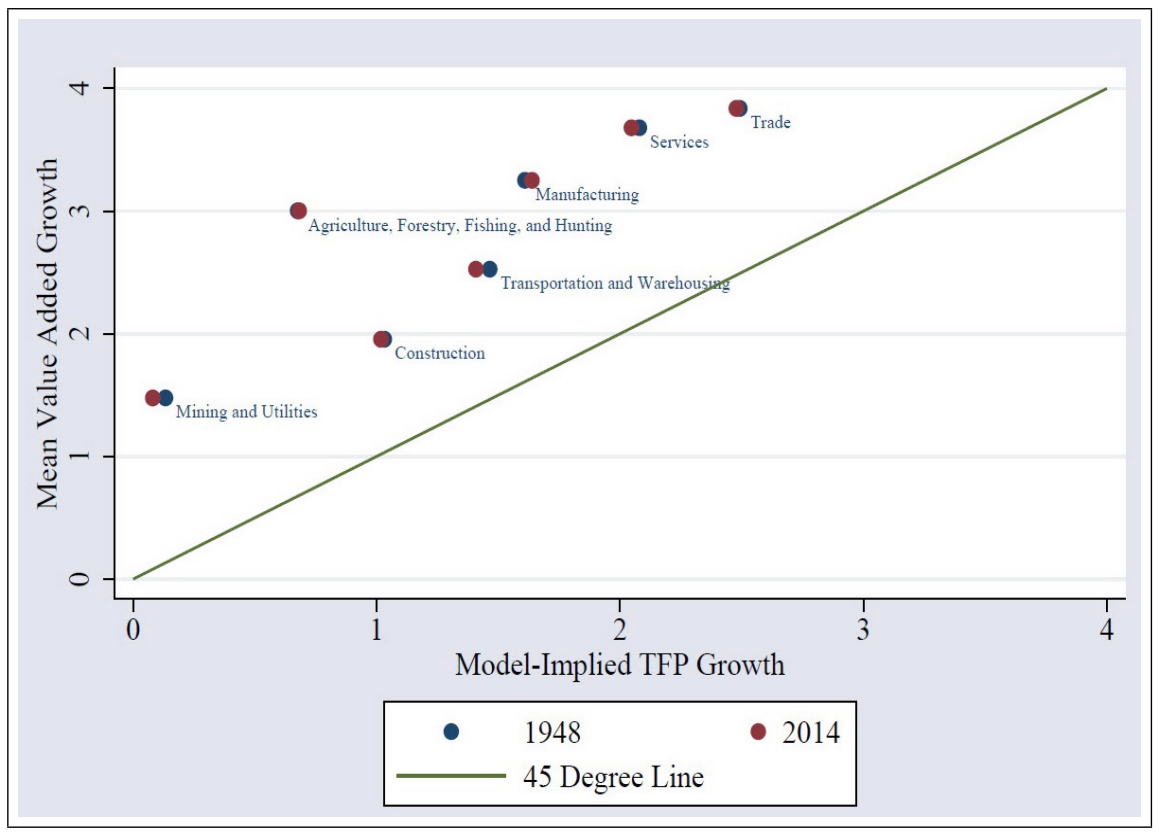

TFP growth in each sector and on the effect of TFP growth changes on GDP growth.

It is worth noting that our analysis here relies on a very high level of aggregation, with only seven sectors, and every sector uses some positive amount of intermediate goods from every other sector. Horvath (1998), Foerster, Sarte, and Watson (2011), and others have found that, at more disaggregated measures of sectors, there is more variability across sectors and the asymmetry of the matrix summarizing intermediate goods linkages substantially increases; many rows consist of mostly zeros, and a few sectors provide most of the economy's intermediate goods. Thus, our results most likely underestimate the degree of heterogeneity in the impact of sectoral changes at lower levels of aggregation. 


\section{REFERENCES}

Acemoglu, Daron, Vasco M. Carvalho, Asuman Ozdaglar, and Alireza Tahbaz-Salehi. 2012. "The Network Origins of Aggregate Fluctuations." Econometrica 80 (September): 1977-2016.

Atalay, Enghin. 2017. "How Important are Sectoral Shocks?" American Economic Journal: Macroeconomics 9 (October): 254-80.

Baqaee, David R., and Emmanuel Farhi. 2018. "The Macroeconomic Impact of Microeconomic Shocks: Beyond Hulten's Theorem." Working Paper 23145. Cambridge, Mass.: National Bureau of Economic Research. (January).

Choi, Jason, and Andrew T. Foerster. 2017. "The Changing Input-Output Network Structure of the U.S. Economy." Federal Reserve Bank of Kansas City Economic Review (Second Quarter): 23-49.

Dupor, Bill. 1999. "Aggregation and Irrelevance in Multi-Sector Models." Journal of Monetary Economics 43 (April): 391-409.

Foerster, Andrew T., Pierre-Daniel G. Sarte, and Mark W. Watson. 2011. "Sectoral versus Aggregate Shocks: A Structural Factor Analysis of Industrial Production." Journal of Political Economy 119 (February): 1-38.

Gabaix, Xavier. 2011. "The Granular Origins of Aggregate Fluctuations." Econometrica 79 (May): 733-72.

Horvath, Michael. 1998. "Cyclicality and Sectoral Linkages: Aggregate Fluctuations from Independent Sectoral Shocks." Review of Economic Dynamics 1 (October): 781-808.

Horvath, Michael. 2000. "Sectoral Shocks and Aggregate Fluctuations." Journal of Monetary Economics 45 (February): 69-106.

Hulten, Charles R. 1978. "Growth Accounting with Intermediate Inputs." Review of Economic Studies 45 (October): 511-18.

Long, John B. Jr., and Charles I. Plosser. 1983. "Real Business Cycles." Journal of Political Economy 91 (February): 39-69.

Lucas, Robert E. Jr. 1981. "Understanding Business Cycles." In Studies in Business Cycle Theory. Cambridge, Mass.: MIT Press, 215-39. 
Miranda-Pinto, Jorge. 2018. "Production Network Structure, Service Share, and Aggregate Volatility." Working Paper. (June).

Ngai, L. Rachel, and Christopher A. Pissarides. 2007. "Structural Change in a Multisector Model of Growth." American Economic Review 91 (March): 429-43.

Pasten, Ernesto, Raphael Schoenle, and Michael Weber. 2018. "Price Rigidity and the Origins of Aggregate Fluctuations." Working Paper 23750. Cambridge, Mass.: National Bureau of Economic Research. (August). 